\title{
PRESENTACIÓN DE MUDIMA
}

\author{
Daniel Weiss Ibáñez \\ MUDIMA
}

\section{INTRODUCIÓN}

Nesta nova Europa que medra e, ao mesmo tempo, se constrúe son cada vez máis o número do que poderiamos chamar «culturas locais». As novas ferramentas tecnolóxicas posibilitan que estas culturas ou formas culturais sexan amosadas, compartidas e preservadas a través de novas vías ou métodos de acceso complementarios cos xa existentes ata agora.

Mazaricos non dispón dunha gran masa patrimonial en termos de obras de arte, grandes monumentos ou feitos históricos de grande relevancia; pero si é certo que o noso patrimonio e a nosa cultura forman parte da nosa historia. Espallados polo territorio hai toda unha serie de elementos patrimoniais que hoxe en día xa non poden ser analizados, polo que as referencias documentais escritas constitúen o noso único vínculo con eses feitos. Por outra banda, nun territorio rural é frecuente atoparse con mostras de construcións típicas, costumes, artesanía, feitos definidos por un tempo e por unha época da historia, que cómpre estudar e estruturar para facer unha divulgación deles.

1 QUE É MUDIMA

O Museo Dixital de Mazaricos (MUDIMA) créase coa finalidade de recuperar e preservar o patrimonio cultural de Mazaricos, utilizando técnicas e medios dixitais, para a súa divulgación a través da rede. As principais motivacións foron:

- Deseñar unha nova vía de acceso á información relacionada co patrimonio local tomando como elemento diferenciador as novas tecnoloxías da información. 
- Promover e difundir o coñecemento do patrimonio cultural da nosa zona facendo máis atractiva a información documental e patrimonial.

- Facilitar o acceso á cultura e ao patrimonio local de xeito que en calquera momento e en calquera lugar sexa posible acceder a esta información.

- Chegar ao público máis novo mesturando cultura e patrimonio co uso das novas tecnoloxías, medio moi atractivo para a poboación nova.

- Servir de ventá aberta para a comunidade de emigrantes no exterior.

- Dixitalizar e sistematizar toda unha serie de documentos e feitos que co paso do tempo tenden a desaparecer: costumes, expresións, formas e ferramentas de traballo, personaxes relevantes, etc.

- Ofrecer unha visión alternativa do noso territorio.

En definitiva, definimos un concepto distinto de museo e para materializar esta idea precisabamos recursos e resolver unha serie de condicionantes de tipo técnico e tecnolóxico.

\section{O PROXECTO CHIMER}

No ano 2002 o Concello foi convidado a formar parte dun consorcio de varios países formado por institucións de diferente índole, entre elas escolas, museos, empresas tecnolóxicas, institucións públicas, fundacións, etc. O obxecto deste proxecto, coñecido co nome de CHIMER, era ofrecer unha nova forma de ver o patrimonio e a cultura, neste caso a través dos ollos dos nenos, baixo a tutela de profesores e especialistas en diferentes materias. O proxecto foi financiado pola Comisión Europea coas axudas do $5^{\circ}$ Programa Marco baixo o epígrafe «Patrimonio para todos». Así, nenos e mestres dos distintos países crearon toda unha serie de contidos multimedia baseados no seu propio patrimonio cultural e usando as novas ferramentas tecnolóxicas: ordenadores, cámaras de vídeo, fotografía, teléfonos móbiles e GPS. Para iso foron crea- 
dos tres eventos en diferentes países coa finalidade de explicar como se debían de elaborar eses contidos usando as diferentes tecnoloxías da información. O resultado final foi un arquivo aberto con contidos multimedia (audio, vídeo, foto e texto) onde nenos e nenas de entre 8 e 12 anos foron capaces de crear temas propios a partir da información subministrada polos mestres e ensinantes; todo iso no propio territorio, usando as posibilidades das tecnoloxías móbiles e sen necesidade de acudir a complexos e aburridos sistemas de bases de datos. Cada elemento patrimonial seleccionado conta cos seus correspondentes arquivos de audio, vídeo, foto e texto xunto coas respectivas coordenadas UTM, que posibilitan a súa localización directa nun mapa vectorial. Froito destas experiencias foron publicados tres libros en que se recolleron os feitos e conclusións de cada unha das tres actividades realizadas (máis información www.chimer.org).

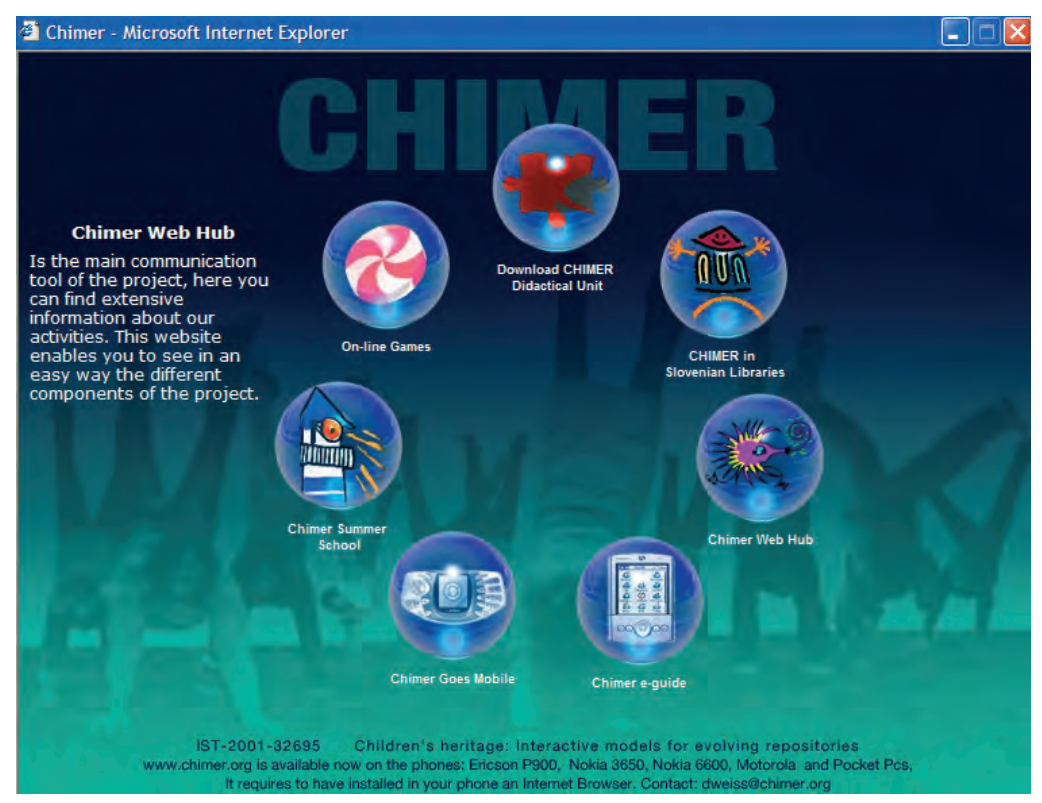


A información recollida, tratada (de ser o caso) e gardada necesitaba dun sistema de almacenamento que fose dinámico, escalable, sostible e, sobre todo, de fácil uso para chegar ao maior número posible de usuarios. Ademais, o requirimento de contar con coordenadas UTM tan só deixaba camiño cara a complexos sistemas de análise territorial, caros e de difícil manexo. A solución adoptada foi a de construír unha nova ferramenta para tal efecto baseada totalmente en tecnoloxía Flash, capaz de amosar todos os contidos multimedia sobre un mapa do territorio e cun deseño moderno e atractivo para os máis novos. O sistema creado permite acceder de maneira fácil á información asociada aos distintos elementos do patrimonio. Con soamente tres clics o potencial usuario pode chegar á información que busca.

\section{A CREACIÓN DE MUDIMA}

Baseándonos na experiencia obtida despois da nosa participación no programa CHIMER empezamos a darlle forma á idea inicial de MUDIMA e a definir os recursos. E cando falamos de recursos facémolo nun senso amplo. Os recursos están constituídos polos diferentes elementos patrimoniais e culturais dentro do territorio e que configuran todo o fondo documental e de información que o proxecto Mudima desenvolve. Pero tamén cómpre ter en conta que para facer fronte a este proxecto foi preciso realizar unha análise previa de medios dispoñibles e necesarios, elementos catalogados e non catalogados, fontes de información e de documentación, tipos de información susceptible de incluír, capas de información, etc. Estas foron as diferentes fases:

1. Análise de contidos susceptibles de incorporación.

2. Estrutura da información. A información foi estruturada en 10 niveis. Debaixo de cada un deles existe un segundo nivel e finalmente unha presentación de contidos baixo o nome de SlideShow ou PhotoGallery. Cada icona da pantalla principal representa un grupo de contidos seguido dun subgrupo e unha enumeración de 
contidos. Este sistema que chamamos «1-2-3» simplifica o acceso á información ofrecendo ao visitante todo un rango de información multimedia en tres clics do rato.

3. Saída ao territorio. O traballo no territorio foi desenvolvido en varias fases. A primeira foi a de comprobación das coordenadas GPS de todos os elementos que formaran parte da plataforma web. Coordenadas, waypoints e rutas foron trazadas, definidas e trasladadas a un mapa vectorial. A segunda fase foi a de preparación da base cartográfica sobre a que descansa toda a plataforma. Os contidos están relacionados polas súas coordenadas UTM sobre un mapa 1:500 tratado previamente para desactivar información non relevante e para facilitar a capacidade e a rapidez da carga na rede.

4. Preparación do material recollido e tipificación. Unha vez recollido todo o material, fíxose a catalogación deste, eliminando aqueles elementos menos relevantes, preparando e adaptando os restantes para a súa inclusión na web.

5. Definición da plataforma multimedia.

4 A PLATAFORMA MULTIMEDIA

A plataforma pódese definir como un soporte xeoinstrumental multimedia capaz de amosar os contidos almacenados de xeito intuitivo e válida para contornos tan diferentes para o usuario como o PC de escritorio ou os dispositivos móbiles. O seu funcionamento é por niveis ou capas de información, sendo cada nivel a agrupación dunha masa de información máis ou menos uniforme en canto a contidos.

Para o seu funcionamento interno a plataforma sérvese dunha serie de ferramentas como son o proxector de contidos multimedia, a galería fotográfica e o sistema cartográfico de información. O proxector de contidos multimedia e a galería fotográfi- 
ca presentan información multimedia en todos os formatos (audio, vídeo, foto e texto) coa única diferencia de que a galería fotográfica non presenta vídeo.

Pola súa banda o sistema cartográfico de información é unha ferramenta gráfica que ofrece a posibilidade de situar cada un dos elementos analizados no territorio de modo similar a un sistema de información xeográfico. Pero ademais ofrece toda unha serie de utilidades que a detallamos a continuación.

\section{OS CONTIDOS}

Unha vez entrado no sitio web, este sería o primeiro nivel de información dispoñible, distribuído en 10 subniveis aos que se accede premendo en cada un dos elementos.

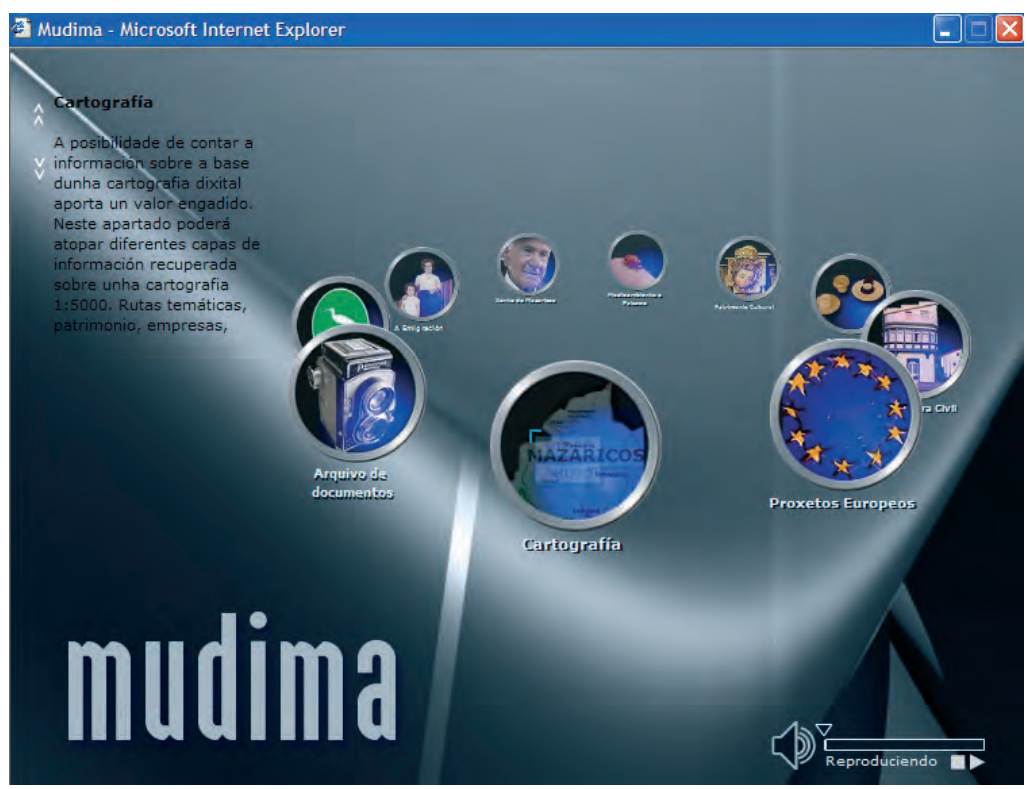

Como podemos ver, son dez os elementos que conforman o primeiro nivel de información: Arquitectura civil, Patrimonio etnográfico, Patrimonio cultural, Medio ambiente e Paisaxe, Xente 
de Mazaricos, A emigración, Web municipal, Arquivo de documentos, Cartografía e Proxectos europeos. Unha vez situados en cada un dos contidos dispomos dun segundo nivel de información.

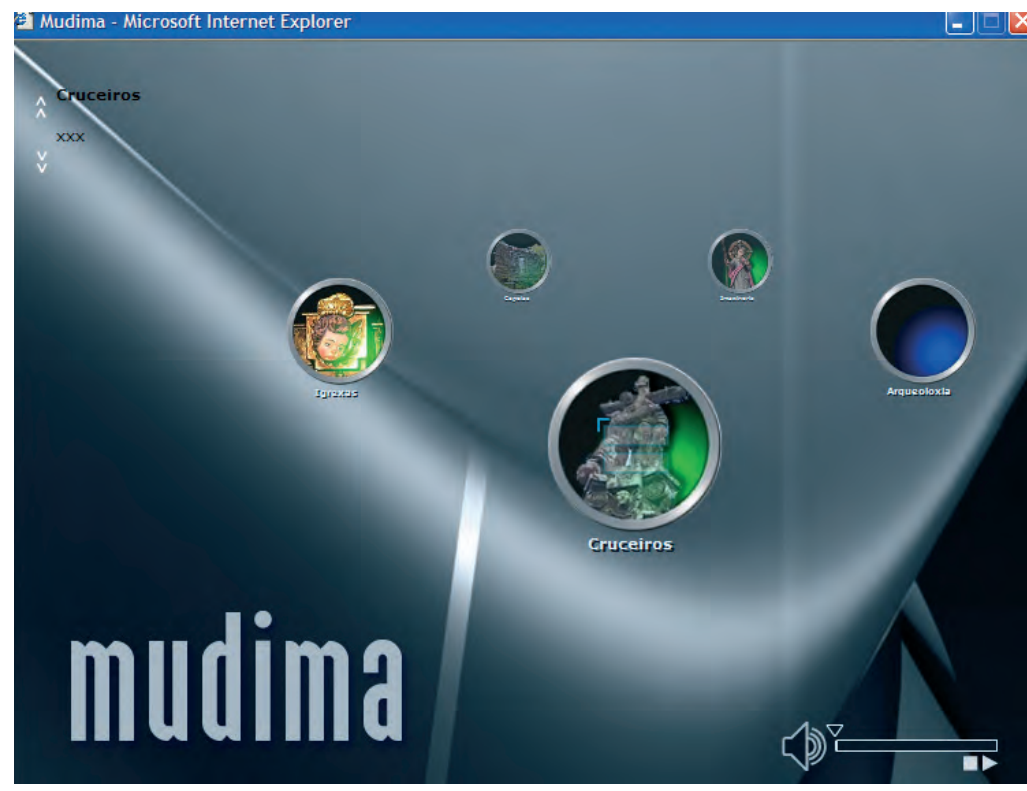

Finalmente un segundo clic en cada un dos apartados do segundo nivel lévanos á información dos diferentes elementos do territorio en distintos formatos: audio, vídeo, texto e foto.

\section{AS UTILIDADES BASEADAS NA CARTOGRAFÍA DIXITAL}

Tal e como se dixo, a plataforma serve de soporte xeoinstrumental da información almacenada. Esta característica é perfectamente visible co uso do sistema de información cartográfico utilizado. Partindo dunha cartografía 1:5000 chégase a ofrecer información multimedia asociada a cada elemento patrimonial usando un ordenador ou mesmo un telefono móbil. Un dos aspectos claves son as coordenadas UTM de cada elemento, pero aínda no caso de non dis- 
por destas o sistema ofrece sistemas de busca alternativos. A susceptibilidade de ser usado a través de dispositivos móbiles abre un novo campo para a creación de contidos en liña no territorio así como toda unha serie de usos alternativos diferentes dos estritamente culturais ou turísticos. O usuario pode desde o propio territorio enriquecer os contidos engadindo novos elementos ou nova información á xa existente. Para isto os requirimentos tecnolóxicos son mínimos: un móbil que dispoña de navegador HTML, cámara dixital e conexión GPRS ou UMTS. No mercado atopamos móbiles que ofrecen estas posibilidades por menos de 100 euros.

Vexamos as posibilidades que o mapa ofrece. Accedemos desde o menú principal premendo en «Cartografía». Esta sería a pantalla inicial, onde dispomos dunha ferramenta de navegación, capas, as coordenadas UTM, un mapa xeral e as diferentes funcións ou utilidades cartográficas. Coa ferramenta de navegación pódese mover polo mapa así como facer zoom sobre unha parte determinada deste.

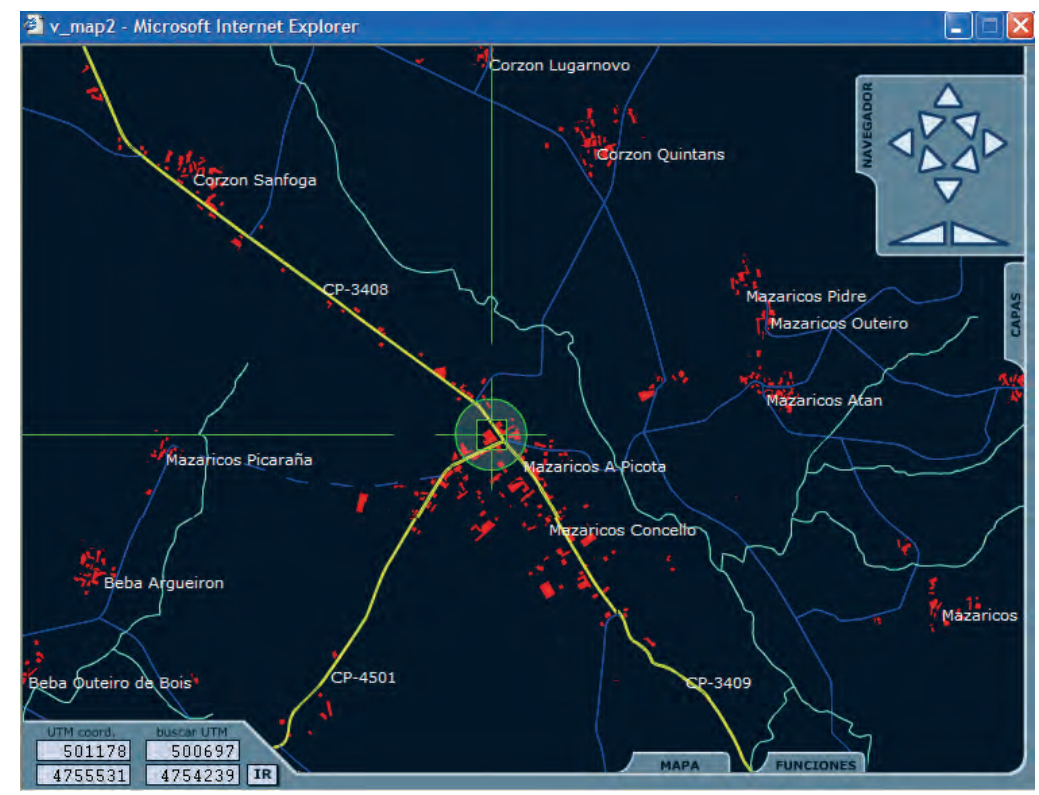


No apartado de capas pódese activar e desactivar diferentes capas de información como estradas, núcleos, ríos e as correspondentes lendas.

O mapa xeral permite unha visión global do territorio de Mazaricos e ofrece a posibilidade de ir directamente a unha zona do territorio delimitada polo cursor en cruz. O mapa situado por debaixo móvese ao mesmo tempo que o mapa xeral. En cada momento o usuario pode visualizar as diferentes coordenadas de cada elemento dos situados no mapa.

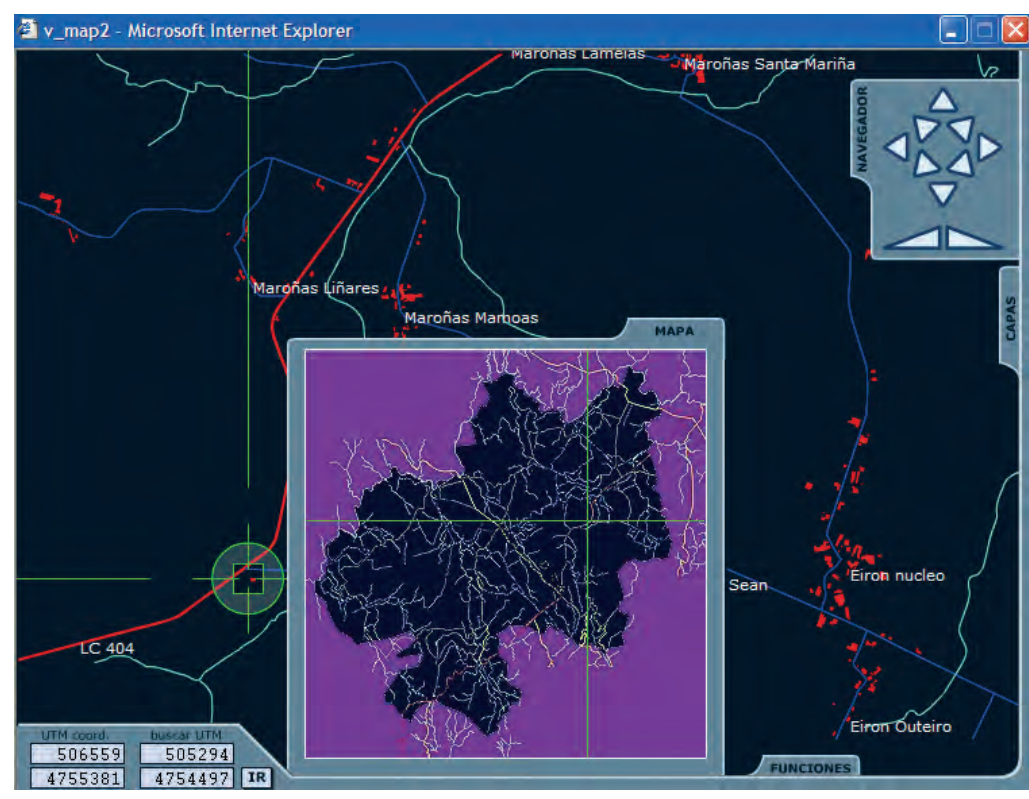

Dentro do grupo «Funcións» atópanse unha serie de utilidades como son rutas polo territorio, un localizador de recursos, servizos de interese, hostalaría, etc. 


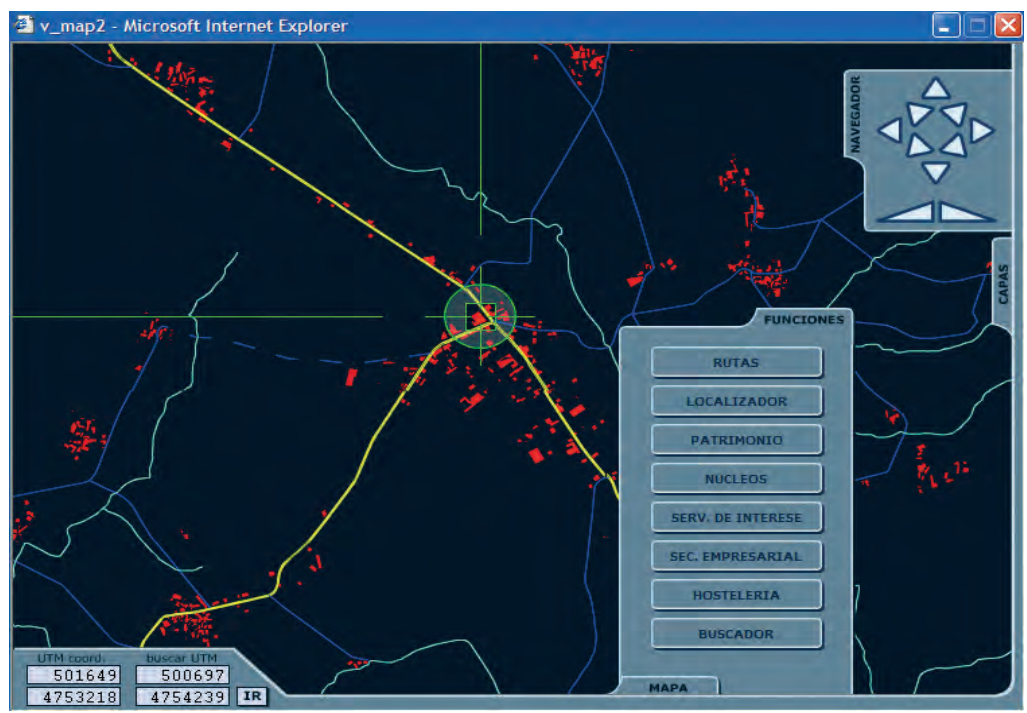

Cinco son as rutas predefinidas. O sistema ofrece a posibilidade de trazar as diferentes rutas no territorio, baixar a ruta para facer no GPS ou vela completa nun documento PDF.

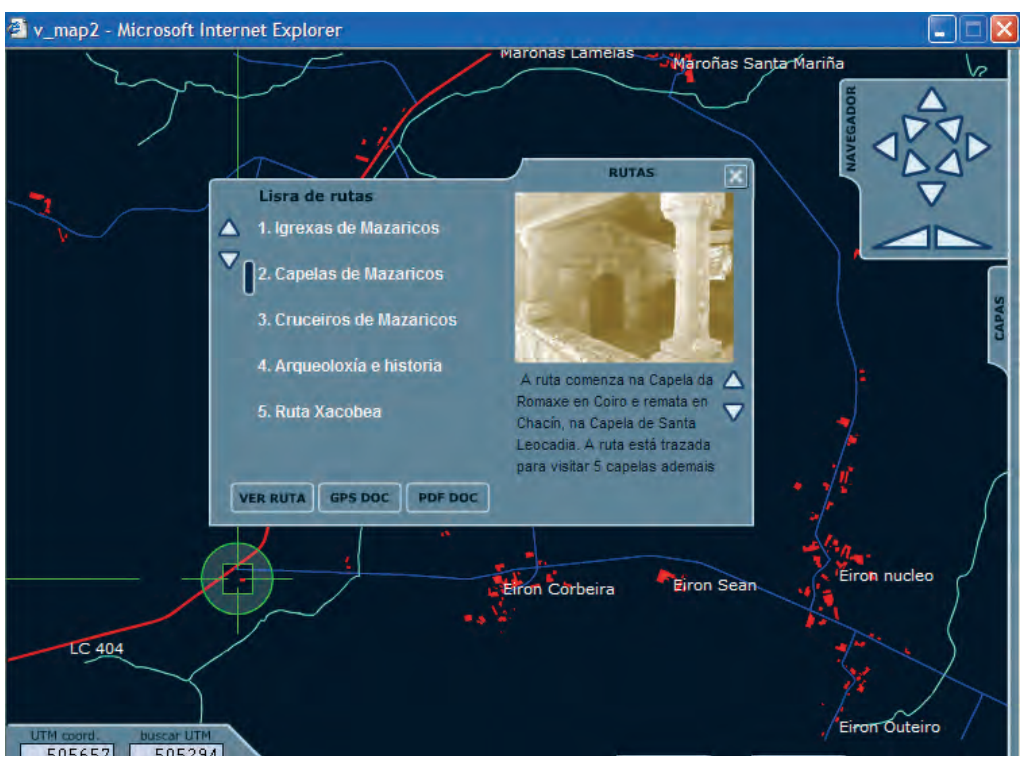


Cada unha delas é trazada no mapa cos diferentes puntos de interese asociados diferenciando coa cor do pin se o elemento se atopa na ruta ou preto desta. Pasando o rato por riba do pin aparece unha fiestra que ofrece unha pequena información de cada elemento.

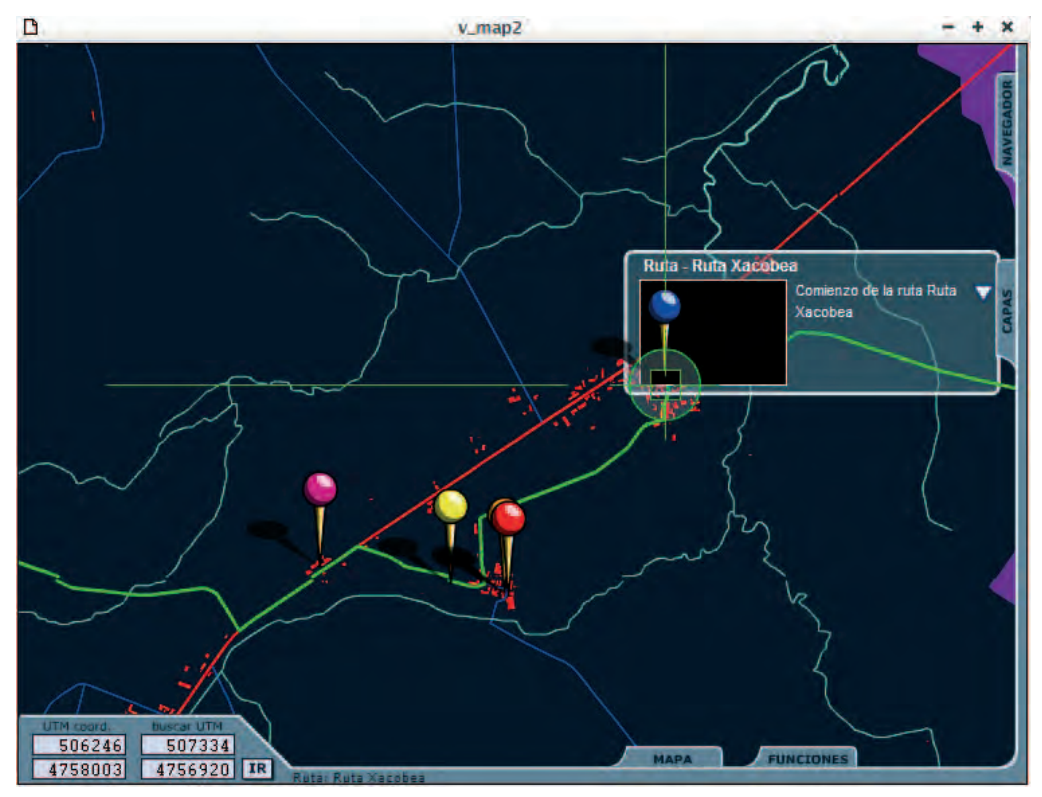

Para visualizar os elementos patrimoniais do territorio existe unha opción organizada alfabeticamente onde despois de premer no elemento en cuestión o cursor sinala no mapa a súa situación exacta xunto coas coordenadas correspondentes. 


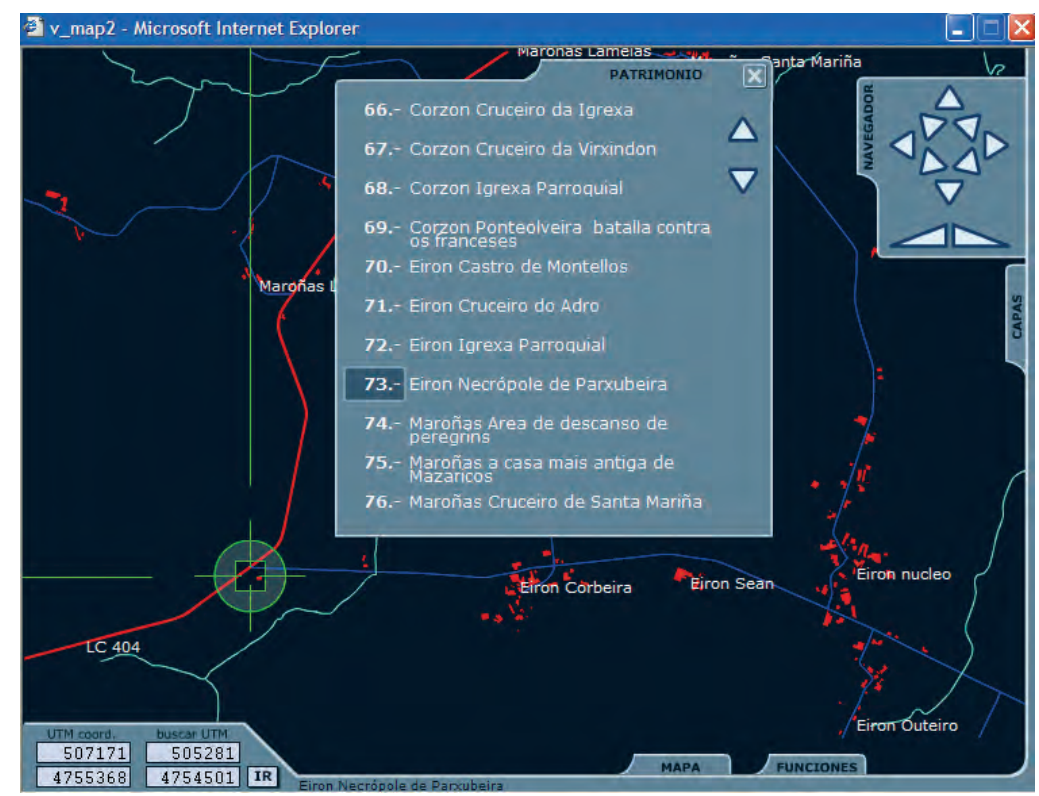

O localizador, pola súa banda, fai unha busca por palabras dentro da base de datos de contidos.

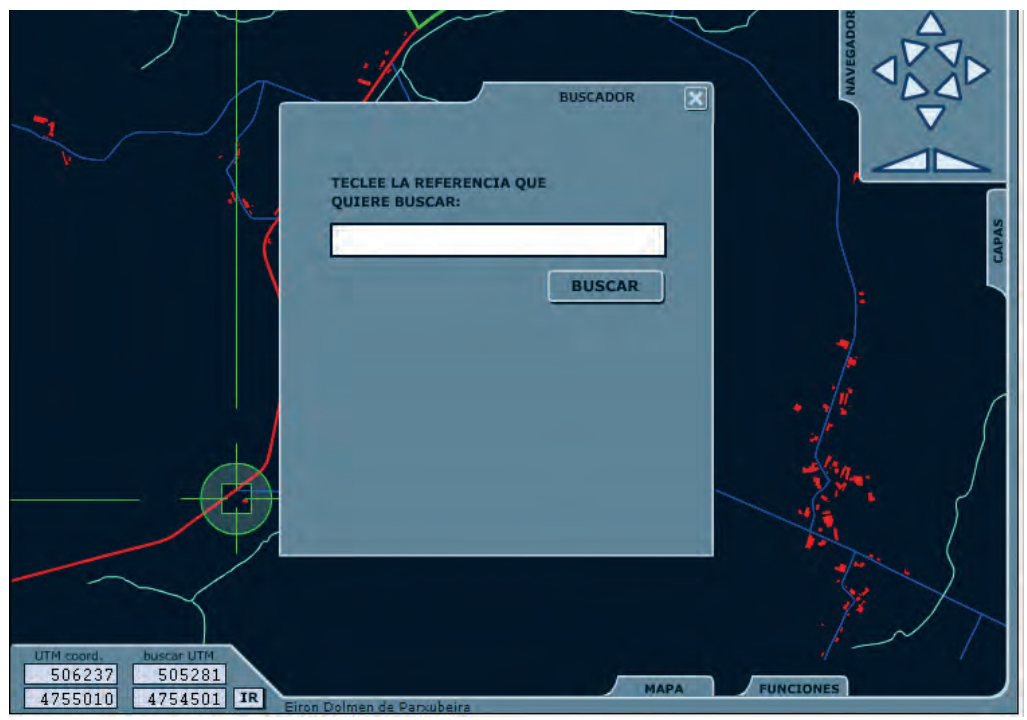


En definitiva, o usuario pode en tres clics de rato acceder á información almacenada e se o precisa visualizar esa información no territorio mediante esta ferramenta. Tal e como se dixo ao inicio, unha nova forma de acceder ao patrimonio mesturando innovación, tecnoloxía e cultura.

O mantemento da plataforma e a incorporación de novos contidos faise tamén dun xeito doado e rápido. O propio sistema dispón dunha ferramenta interna que interactúa co usuario e facilita tanto o mantemento como a incorporación de nova información evitando a dependencia de xestores ou administradores externos.

7 A PLATAFORMA MÓBIL

No caso de tratarse dun dispositivo móbil, a plataforma está deseñada para presentar a información no tamaño e peso axeitados, tendo en conta que no caso dun acceso vía GPRS ou UMTS o tamaño dos arquivos condiciona o custo do servizo. Non obstante, o usuario non depende exclusivamente da existencia dunha conexión GPRS ou UMTS para acceder á información, senón que tamén pode descargar os contidos en que estea interesado e usar o seu móbil ou PDA como guía no territorio.

O acceso a través dun dispositivo móbil permite conseguir a información de igual xeito que desde un ordenador, se ben neste caso estes dispositivos aínda non executan tecnoloxía flash de maneira directa, polo que as iconas que aparecen representando a cada grupo de contidos son estáticas. Esta sería a pantalla correspondente ao primeiro nivel de información: 


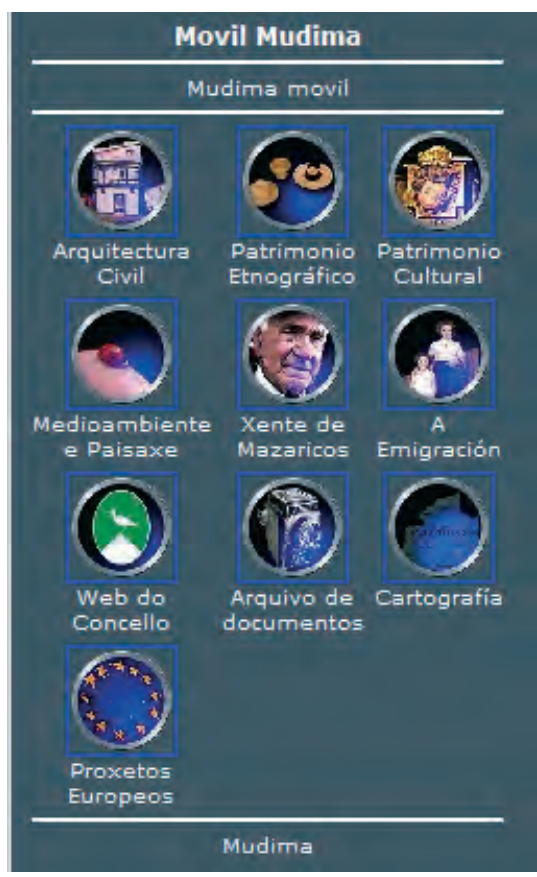

Unha vez que se entrou nos diferentes apartados, accédese a un segundo nivel ou subgrupo de contidos:

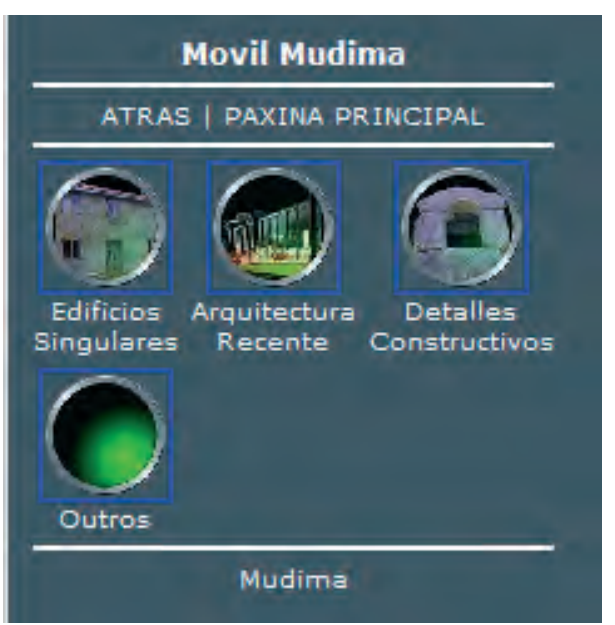


Finalmente, a información pode ser vista nun mapa no mesmo dispositivo móbil. O sistema mostra un cadro de diálogo solicitando as coordenadas UTM; unha vez que entraron as coordenadas, amosa un mapa sinalando a situación xeográfica así como unha lista de elementos de interese próximos.

No caso de dispor dunha ortofoto, a plataforma colocaríaa dentro do visor.
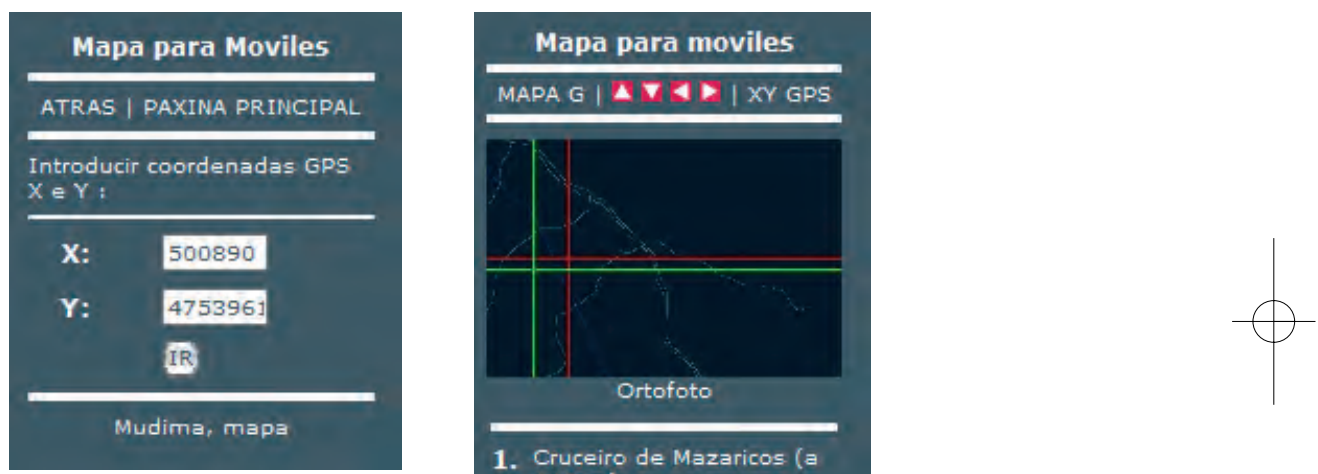

1. Cruceiro de Mazaricos (a $119 \mathrm{~m}$ )

ver datos I GPS mapa

2. Ruta - Igrexas de Mazaricos (a $158 \mathrm{~m})$

ver datos I GPS mapa

3. Zona recreativa Ponte do Cura (a $437 \mathrm{~m})$ ver datos | GPS mapa

4. Ruta - Arqueoloxía e historia (a $687 \mathrm{~m}$ ) sin datos I GPS mapa

5. Capela da Virxindón (a $800 \mathrm{~m}$ ) ver datos I GPS mapa

6. Capela da Virxindón (a $800 \mathrm{~m}$ ) ver datos | GPS mapa 